OPEN ACCESS

Edited by:

Q. Adam Ye,

Harvard Medical School,

United States

Reviewed by:

Jianxun Ding,

Chinese Academy of Sciences, China

Xingang Wang,

Zhejiang University, China

${ }^{*}$ Correspondence:

Xiaobing $\mathrm{Fu}$

fuxiaobing@vip.sina.com

Sha Huang

stellarahuang@sina.com

tThese authors have contributed equally to this work and share first

authorship

Specialty section:

This article was submitted to

Stem Cell Research

a section of the journal

Frontiers in Cell and Developmental

Biology

Received: 11 December 2020

Accepted: 09 February 2021

Published: 25 March 2021

Citation:

Li J, Liu Y, Zhang Y, Yao B, Enhejirigala, $L i Z$, Song $W$, Wang $Y$, Duan X, Yuan X, Fu X and Huang S (2021) Biophysical and Biochemical

Cues of Biomaterials Guide

Mesenchymal Stem Cell Behaviors.

Front. Cell Dev. Biol. 9:640388.

doi: 10.3389/fcell.2021.640388

\section{Biophysical and Biochemical Cues of Biomaterials Guide Mesenchymal Stem Cell Behaviors}

\author{
Jianjun Li1,2,3†, Yufan Liu1,2†, Yijie Zhang ${ }^{1,2}$, Bin Yao ${ }^{1,2,4}$, Enhejirigala ${ }^{1,2,5,6}$, Zhao Li1, \\ Wei Song ${ }^{1,2}$, Yuzhen Wang ${ }^{1,2,7}$, Xianlan Duan ${ }^{1,2,8}$, Xingyu Yuan ${ }^{1,2,8}$, Xiaobing Fu ${ }^{1,2,9 *}$ and \\ Sha Huang ${ }^{1 *}$
}

\begin{abstract}
'Research Center for Tissue Repair and Regeneration, Medical Innovation Research Department and the Fourth Medical Center, Chinese PLA General Hospital, PLA Medical College, Beijing, China, ${ }^{2}$ PLA Key Laboratory of Tissue Repair and Regenerative Medicine and Beijing Key Research Laboratory of Skin Injury, Repair and Regeneration, Chinese PLA General Hospital, PLA Medical College, Beijing, China, ${ }^{3}$ Department of General Surgery, The Sixth Medical Center, Chinese PLA General Hospital, Beijing, China, ${ }^{4}$ The Shenzhen Key Laboratory of Health Sciences and Technology, Graduate School at Shenzhen, Tsinghua University, Shenzhen, China, ${ }^{5}$ College of Graduate, Tianjin Medical University, Tianjin, China, ${ }^{6}$ Institute of Basic Medical Research, Inner Mongolia Medical University, Hohhot, China, ${ }^{7}$ Department of Burn and Plastic Surgery, Air Force Hospital of Chinese PLA Central Theater Command, Datong, China, ${ }^{8}$ School of Medicine, Nankai University, Tianjin, China, ${ }^{9}$ Research Unit of Trauma Care, Tissue Repair and Regeneration, Chinese Academy of Medical Sciences, Beijing, China
\end{abstract}

Mesenchymal stem cells (MSCs) have been widely used in the fields of tissue engineering and regenerative medicine due to their self-renewal capabilities and multipotential differentiation assurance. However, capitalizing on specific factors to precisely guide MSC behaviors is the cornerstone of biomedical applications. Fortunately, several key biophysical and biochemical cues of biomaterials that can synergistically regulate cell behavior have paved the way for the development of cellinstructive biomaterials that serve as delivery vehicles for promoting MSC application prospects. Therefore, the identification of these cues in guiding MSC behavior, including cell migration, proliferation, and differentiation, may be of particular importance for better clinical performance. This review focuses on providing a comprehensive and systematic understanding of biophysical and biochemical cues, as well as the strategic engineering of these signals in current scaffold designs, and we believe that integrating biophysical and biochemical cues in next-generation biomaterials would potentially help functionally regulate MSCs for diverse applications in regenerative medicine and cell therapy in the future.

Keywords: microenvironment, biomaterial, stem cell therapies, cell behavior, tissue engineering

\section{INTRODUCTION}

Mesenchymal stem cells (MSCs) have received increasing attention in the field of regenerative medicine and tissue engineering due to their high self-renewal ability and multipotential differentiation lineage, as well as accessibility. Numerous studies have shown that they have been applied in repairing cartilage, bone, adipose, muscle, skin, liver, nerve, and other organs (Han et al., 2019). For instance, Wingate et al. (2012) obtained endothelial and muscle-like cells by culturing MSCs on a three-dimensional (3D) hydrogel; Duarte Campos et al. (2015) can accurately guide 
MSCs toward osteogenic and adipogenic differentiation lineage. Those researches both utilized MSCs as seed cells to successfully harvest corresponding tissue cells, which will provide important cell sources and functional support for subsequent clinical treatment.

However, MSC-based tissue engineering still has its own shortcomings that cannot be ignored. One of the problems is that only a few injected MSCs can home and stabilize on the target tissue and play a therapeutic role (De Becker and Riet, 2016). More important, the uncertainty of the differentiation of MSCs after infusion complicates functional reconstruction. Currently, more and more studies documented that biomaterials could be used to protect transplanted MSCs, especially to maintain the viability of MSCs and accurately induce the MSC to differentiate into specific targeted cells. These potentials are mainly attributed to the ability of biomaterials to mimic a multitude and systematic extracellular milieu to guide MSCs in tissue regeneration. For example, engineered scaffolds derived from different biomaterials lead to the satisfying outcome of MSC-based repair in cartilage regeneration due to the excellent biocompatibility and chondrogenesis induction (Le et al., 2020). In addition, Li et al. (2005) fabricated a biodegradable synthetic scaffold that provides an important microenvironment for MSCs in cartilage repair. Subsequently, the cartilage formation was successfully observed on the scaffold, which provided a practical MSC-based tissue engineering approach for cartilage repair. In addition to the cartilage, Prabhakaran et al. (2009) fabricated a nanofibrous scaffold by electrospinning and successfully observed MSC-derived neural morphology and functional cells for nerve repair. Either as guidance cues or as delivery vehicles for controlling the fate of transplanted cells, biomaterials play a major role in the development of MSCbased therapy.

There is no doubt that numerous factors of biomaterials such as the cellular microenvironment can alter MSC behaviors. These factors include biophysical cues (e.g., stiffness, pore size, porosity, and topography) and biochemical cues (e.g., growth factors, growth factor derivatives, small bioactive molecules, and genetic regulators). Many biochemical cues have been determined over the past century, and a number of studies have reported that biochemical stimulation delivered by biomaterials can influence stem cell attachment, proliferation, and differentiation, and is generally effective and easy to deliver. However, biophysical cues have a longer lifetime and can be easily well defined. For instance, Gilbert et al. (2010) have demonstrated that stiffness of substrate has a significant effect on the fate of muscle stem cell. They elucidated that the soft hydrogel substrate mimics physiological elasticity and can obviously promote the propagation of muscle stem cell, and after transplantation, it contributed extensively to muscle regeneration. Gupte et al. (2018) demonstrated that the chondrogenesis and endochondral ossification of bone marrow stromal cells can be modulated by scaffold pore architecture, specifically pore size. Meanwhile, they found that the pore interconnectivity is essential for capillary ingrowth during bone formation. Thus, MSC-based tissue engineering will be greatly enhanced by the biomaterial design. However, the different designs in a variety of studies have led to difficulties in obtaining clear conclusions about the effects of the different cues and on regulating MSC behaviors. Therefore, it is necessary to focus on summarizing these biophysical and biochemical factors and their significant effects. An overall summary of topics covered in this review is presented in Figure 1. We propose that a deep understanding of various factors of biomaterials is of great significance to better release the potential of MSCs in tissue engineering, and the precise integration of cues according to the needs of different target tissues can open up new avenue for future MSC-based therapy.

\section{BIOPHYSICAL CUES}

Compared to biochemical cues of biomaterials, biophysical cues have a longer lifetime and can be easily defined. Biophysical cues, such as stiffness, pore size, porosity, topography, as well as stress relaxation, are often regarded as primary elements in biomaterial design for tissue engineering.

\section{Stiffness}

It is well known that, as Discher et al. (2005) claimed, cells can sensitively feel and respond to the stiffness of extracellular matrix. Similarly, the behavior of MSCs can also be altered by stiffness. Engler et al. (2006) cultured naive human MSCs (hMSCs) on matrix with three different levels of stiffness (0.1-1, 8-17, and 25$40 \mathrm{kPa}$ ). Finally, hMSCs cultured on the soft substrate, mimicking the brain stiffness at a level about $0.1-1 \mathrm{kPa}$, exhibited extensive branching and are filopodia-rich, much like primitive neuronal morphology. Stiffer materials that simulate muscle $(8-17 \mathrm{kPa})$ and collagenous bone $(25-40 \mathrm{kPa})$ guided hMSCs exhibiting myoblast-like and osteoblast-like morphology, causing cells to express myogenic marker (MyoD) and osteogenic marker (Runx2 ), respectively. Meanwhile, different levels of stiffness can also produce changes in hMSC proliferation. Whitehead et al. seeded hMSCs on the surfaces of common cell culture dishes and polyethylene glycol (PEG)-based hydrogel platform, which have two different levels of stiffness (8-10 and 50-60 kPa). Ultimately, the stem cells on soft hydrogels exhibited more proliferation activity compared to stiffer hydrogels (Whitehead et al., 2018). Stiffness in 3D matrix also has a significant impact on behavior of MSCs. Wingate et al. (2012) synthesized a 3D nanofiber hydrogel matrix with tunable stiffness by varying the time of photopolymerization and stated that hMSCs on the rigid matrices $(8-15 \mathrm{kPa})$ showed a larger extension area and more polarization compared to the soft matrices $(2-5 \mathrm{kPa})$. Meanwhile, the smooth muscle marker (SMA) and SMA mRNA were significantly upregulated. By contrast, the expression of vascular-specific marker (FLK-1) and FLK-1 mRNA was significantly increased on soft substrate. Those results demonstrated that the stiffness of matrix can functionally regulate the behavior of MSCs, and the cells tend to exhibit corresponding morphology, proliferation rate, and differentiation lineages when they are cultured on substrate with similar stiffness to their native niches.

The mechanism of microenvironment affecting the behavior of MSCs mainly focuses on the direction of differentiation. Numerous studies have proposed that stiffness of matrices 


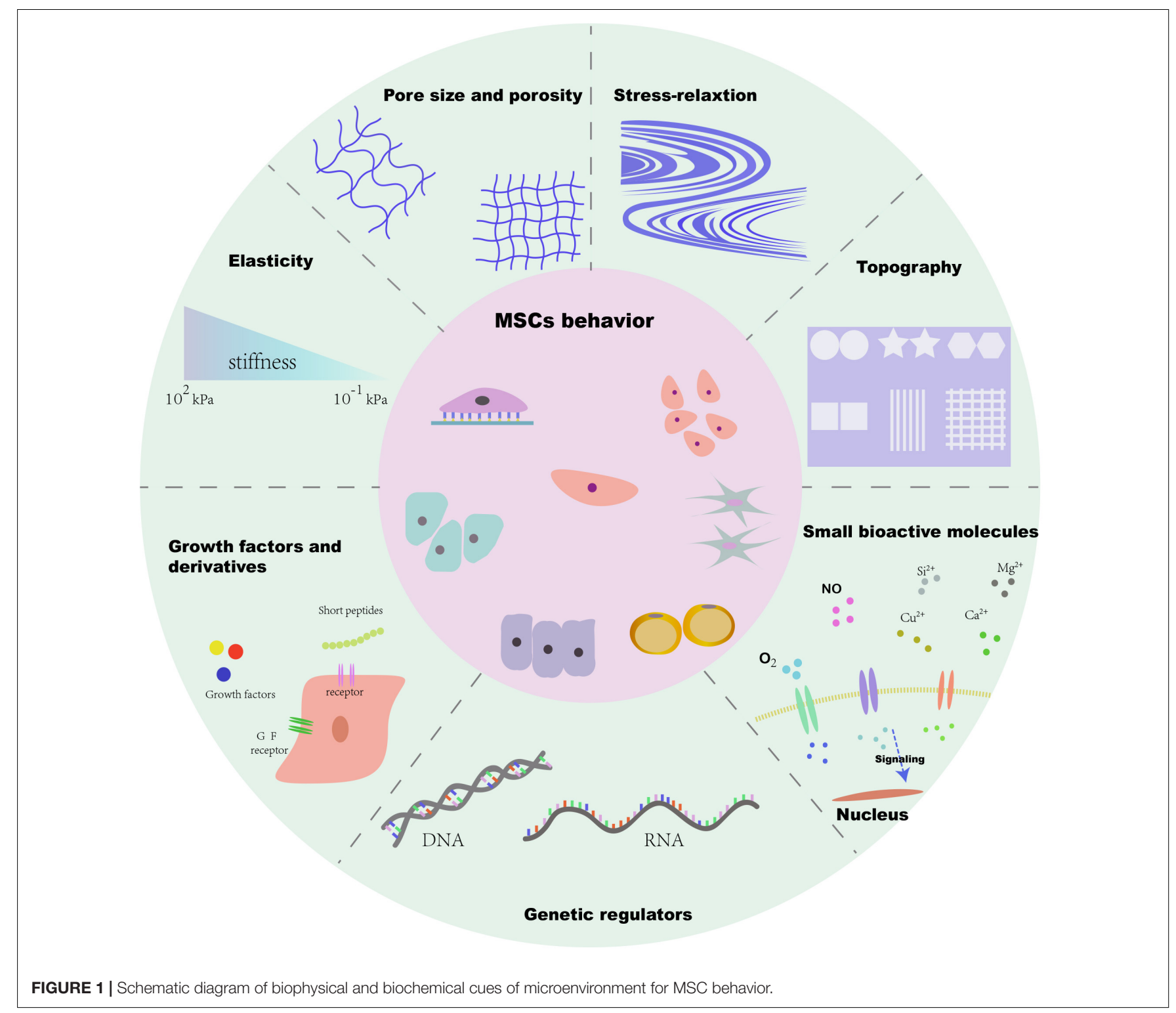

can modulate self-renewal and differentiation of MSCs via the integrin-mediated signal pathways. Integrins are a family of heterodimeric surface molecules and the most important triggers located in the starting position of mechanotransduction (Du et al., 2011; Higuchi et al., 2013; Sun et al., 2018). For example, Shih et al. (2011) proved that activation of the $\alpha 2$-integrin-mediated Rho kinase (ROCK)-focal adhesion kinase (FAK)-ERK1/2 mechanotransduction pathway could significantly enhance osteogenic differentiation of MSCs, by cultured MSCs on hydrogels with different stiffness. Similarly, Du et al. demonstrated that $\beta 1$-integrin activation was significantly enhanced in MSCs on soft hydrogels $(0.1-1 \mathrm{kPa})$ compared to hard substrates $(50-100 \mathrm{kPa})$. In addition, soft culture substrates can induce neural differentiation of MSCs by inhibiting the $\beta 1$ integrin-modulated bone morphogenetic protein (BMP)-Smad pathway (Du et al., 2011). Currently, experts believe that the stiffness of substrate could provide different mechanical stimuli changes in focal adhesion protein (FAP) activities and remolding, and then MSCs sense the changes via integrins, the primary kind of FAP on cell membrane.

\section{Stress Relaxation}

Recently, increasing evidences have shown that stress relaxation of substrate is also a significant mechanical parameter in guiding the behavior of MSCs. Previous researches have mainly focused on the stiffness, which represents the characteristics of purely elastic biomaterials, while most ECMs and tissues are viscoelastic. During the compression process, viscoelastic tissues, such as brain, muscles, and cartilage, require a constantly decreased stress to maintain a certain strain. In other words, native ECM and tissues that maintain constant strain will exhibit stress relaxation or time-dependent deformation, which is another important mechanical property of biomaterials (Chaudhuri et al., 2015; Chaudhuri et al., 2016; Bauer et al., 2017). 
Some excellent articles have elucidated the influence of stress relaxation on the behavior of MSCs. Chaudhuri et al. (2016) cultured murine MSC in the hydrogel with tunable stress relaxation but similar initial elastic modulus and found that the faster stress relaxation substrate strikingly enhanced both spreading and proliferation of MSCs compared to the low relaxation hydrogel. In addition, an interconnected, mineralized, and collagen-1-rich matrix was detected in the rapidly relaxing gel, which indicated that the rapid stress relaxation enhanced not only the osteogenesis of MSCs but also the bone-forming activity. In another study, Cameron et al. proposed a polyacrylamide gel system with constant storage moduli but varying loss moduli. The varying loss moduli ultimately changed the creep and deformation of the gel, which represented the stress relaxation property (Cameron et al., 2011). Eventually, they found that the spreading area of MSCs increased with the augmentation in modulus loss and stress relaxation of the substrate. Meanwhile, there was an obvious trend that the proliferation of MSCs was increased on the higher stress relaxation substrate. Furthermore, the differentiation potential of MSCs, such as adipogenesis, osteogenesis, and myogenesis, was also amplified on the higher loss moduli substrates compared to the low loss moduli substrates. Besides, in the calvarial defect repair test in vivo, Darnell et al. (2017) found that the rapid-relaxing hydrogel carrying MSCs promoted new bone formation better than the slow-relaxing but stiffness-matched hydrogel. Overall, those studies have shown that the stress relaxation or creep of the substrate can significantly affect the behavior of MSCs in tissue engineering.

With the deepening of the researches, the driving factors behind stress relaxation are gradually being exposed. Although the effects of matrix stiffness and stress relaxation on MSCs are all related to cell focal adhesion and the tension generated by the cytoskeleton or tension fiber, the molecular mechanisms and signal pathways behind them are not completely the same due to the different inherent physical properties. Cameron et al. (2014) demonstrated that the activated mechanotransductive signaling molecules (Rac1) pathway on rapid creep substrates exerted a valid mechanism, helping to the enhance the differentiation of hMSCs toward smooth muscle cell lineage. Chaudhuri et al. (2016) suggested that in the rapidly relaxing gel, the increased binding and clustering of integrins as well as the cell mechanoreceptor actomyosin contractility contributed to the osteogenesis of hMSCs. Compared with the mechanism of stiffness on MSCs, the mechanism of stress relation on cells is different, but there are some overlaps. Therefore, more researches are needed to explore the specific mechanism of stress release.

\section{Topography}

With the progress of the material manufacturing technology and the improvement of resolution, more and more biomaterials with different micro- and nano-patterned surfaces have been manufactured. To explore the influence of terrain on MSCs, various shapes and morphologies, such as squares, stars, stripes, and grids, have been reported (Tang et al., 2010; Tay et al., 2010; Wan et al., 2010). Meanwhile, there is increasing evidence that shows that the geometric characteristics or the topography of the extracellular microenvironment can directly alter the response of MSCs from proliferation, extension, differentiation, and paracrine.

The cell shapes, spreading area, cell-cell interaction, and orientation of arrangement direction are the main targets for biomaterial topography to influence MSCs. Due to the domestication of the surrounding topographical features, MSCs finally adapt to the micro- and nano-patterned surfaces by changing its own morphology, thus changing its own destiny. McBeath et al. (2004) cultured hMSCs on micropatterned materials with square shape ranging from 1000 to 10,000 $\mu \mathrm{m}^{2}$, and cells with different spreading area and differentiation commitments were obtained after 1 week. Osteogenesis was observed mostly on larger micropatterned substrates, whereas adipogenesis was found on smaller substrates, suggesting that cell spreading area induced by the micropatterned microenvironment can change the fate of MSCs. However, the spreading area varies with the shape. Thanks to the development of print technique, we can decouple these two parameters. Kilian et al. seeded individual MSCs on different rectangles but with constant area using the microcontact printing technique. Eventually, they found that the osteogenic differentiation of MSCs increased with the aspect ratio (1:1, 3:2, and 4:1), indicating that the shape of materials can independently affect the fate of MSCs (Kilian et al., 2010). Moreover, the development of manufacturing technology also makes it possible to reveal the effects of the cell-cell interaction. Tang et al. (2010) designed five different micromodel domains composed of microisland, allowing a single MSC to bind to each microisland, so that the average number of cell contacts in each micromodel domain is different. Finally, they observed that the osteogenesis and adipogenesis of MSCs are linearly related to the number of cellcell contacts and gap junctions. In addition, in order to study the effects of alignment direction, Zhu et al. (2005) aligned and cultured MSC-derived osteoblast-like cells along the direction of nanogrooves in the scaffold. Finally, they pointed out that the cells implanted in the laser-treated nanogrooves had a higher proliferation rate than those in normal disk, suggesting that the nanoscale alignment along the longitudinal direction can promote the aligned formation of bone tissue. However, contrary to the above results, Jahani et al. (2012) showed that random nanofibrous scaffolds were more suitable for the growth of rat MSCs than aligned scaffolds and had higher proliferation. The reason may be that the random fibers contain more interconnected pores for circulation of nutrients. In addition, the significance of topography, such as the mussel-inspired nanostructures of functionalized 3D-printed bioceramic scaffolds developed by Li et al. (2019), could accelerate tissue regeneration by regulating the paracrine of adipose-derived MSCs. Based on the above researches, the topography of the matrix can affect the behavior of MSCs in different ways.

Because the topography are mainly physical stimulations, the underlying mechanism is related to the cytoskeletal contractility and the response of MSCs to mechanical forces. Kilian et al. (2010) demonstrated that topographical features of substrates increased MSCs' actomyosin contractility so as to promote the osteogenesis of MSCs. At the same time, the increased 
cytoskeletal tension is related to the enhanced c-Jun N-terminal kinase (JNK) and the activation of extracellular-related kinase (ERK1/2), as well as the elevated wingless-type (Wnt) signaling (Kilian et al., 2010). Thanks to the advance in biomaterials preparation, we can gain insight into the underlying mechanism of topography and give full play to its role in MSC-based regenerative medicine.

\section{Pore Size and Porosity}

The pore size and porosity have been valued by researchers for a long time. As early as 1971, Weber et al. (1971) pointed out that the structure of the porous medium is crucial. They stated that the interconnected pores with appropriate size, shape, and uniformity are essential for cell growth and adhesion. Since then, lots of experts have devoted themselves to studying the effects of pore characteristics on MSCs, in order to reveal its potential in the field of manufacturing biomaterials.

Although the optimal pore size of scaffolds varies with the biomaterials and cell type, the pore size and porosity are closely related to the cellular behavior of MSCs. Murphy et al. (2016) manufactured a series of collagen-glycosaminoglycan (CG) scaffolds with mean pore size ranging from 85 to 325 $\mu \mathrm{m}$ and found that the pore size exhibits a non-linear and bimodal effect on MSC adhesion. Specifically, MSCs adhered most to scaffolds with an average pore size of $325 \mu \mathrm{m}$, whereas another peak appeared at $120 \mu \mathrm{m}$. This phenomenon was due to the fact that the small pores have a larger surface area and the large pores have a higher ligand density. Similarly, Zhang et al. (2016) stated that the smaller pore size in the framework provided a larger surface area for cell adhesion. In addition, the pore size of biomaterials also changes the proliferation efficiency of MSCs. Zhang et al. fabricated a set of scaffolds with three different mean pore sizes (i.e., 215, 320, and 515 $\mu \mathrm{m})$. Eventually, they claimed that the proliferation efficiency in the $515 \mu \mathrm{m}$ scaffold was significantly lower than the other two groups. In other words, MSCs prefer to proliferate within the small pores of scaffolds. On the other hand, as demonstrated by O'Brien et al. (2007) the large pore size is superior to small pores in MSC migration or infiltration into the interior of the scaffold (Murphy et al., 2016). Therefore, when manufacturing the scaffold, we need to achieve a balance between utilizing large pores to improve cell migration and penetration and small pores to promote cell adhesion and proliferation. Meanwhile, the porosity also proved to be related to the behavior of MSCs. The highly porous patterns fabricated by electrospinning technology have been comprehensively assessed and proved to facilitate bone engineering (Ding et al., 2019). As we all know, the increase in porosity is beneficial to the nutrient diffusion and the waste removal within a certain range and achieves good proliferation of MSCs (Zhao et al., 2021). Kasten et al. (2008) implanted MSCloaded $\beta$-tricalcium phosphate (TCP) scaffolds with different porosities $(25,65$, and $75 \%)$ into SCID mice and found that the TCP 65 and TCP 75 with high porosity had higher ALP activity than the TCP 25 after 8 weeks. Obviously, the increase in porosity is conducive to the osteogenesis of MSCs in vivo. Like porosity, numerous studies have confirmed that the change of pore size can also guide the differentiation commitment of MSCs.
Matsiko et al. (2015) cultured MSCs in Collagen-hyaluronic acid (CHyA) scaffolds with three different average pore sizes (94, 130 , and $300 \mu \mathrm{m}$ ) and demonstrated that the maximum pore sizes $(300 \mu \mathrm{m})$ significantly enhanced the expression of cartilageforming genes and cartilage-like matrix deposition. In another research, Mygind et al. (2007) pointed out that the $200-\mu \mathrm{m}$ pore hydroxyapatite scaffold exhibited faster osteogenic differentiation than the 500- $\mu \mathrm{m}$ pore scaffold, while the latter had a higher proliferation capability. It seems that there is an optimal pore range for MSC differentiation, and this range varies with the cell types and biomaterials. Pore size and porosity, as the specific form of pore structure, have a significant impact on the behavior of MSCs attached to biomaterials.

\section{BIOCHEMICAL CUES}

It has been many years since the biochemical modulation of stem cell growth and differentiation using small molecules and growth factors. However, due to the shortcomings of burst release and difficultly of long-term control or definition, biochemical factors have always been integrated into biomaterial-based scaffolds. Compared to biophysical cues, biochemical cues of biomaterials are easier to deliver. Besides growth factor and small bioactive molecules, genetic regulators have also been discussed in this section.

\section{Growth Factor and Derivatives}

Some progress has been made in promoting MSC-based regeneration by adding growth factors and derivatives, such as EGF, VEGF, FGF, and TGF $\beta$. For example, soluble EFG can not only promote the proliferation of MSCs without compromising its pluripotent differentiation but also increase paracrine secretion to accelerate tissue regeneration (Tamama et al., 2010). However, conventional administration methods deliver growth factors and derivatives in soluble form, leading to complications such as hypotension and nephrotoxicity (Ferrara and Alitalo, 1999). So, combination of scaffold with growth factors would become an alternative and effective method and has made clear progress in areas such as bone regeneration of osteonecrosis (Zhu et al., 2020). Therefore, as a novel delivery method, the integration of growth factors into biomaterials can recapitulate a more suitable environment for MSCs at a physiologically relevant concentration and duration.

Fan et al. (2007) fabricated a scaffold covalently modified with epidermal growth factor (EGF) to control the release of EGF more precisely, which could increase MSCs spreading and adhesion through elevated ERK signaling and enhanced resistance to FasL-mediated cell death relative to saturating concentrations of soluble EGF. These advances can be attributed to the combination of EGF molecules with structures that bind and activate EGF receptors and the production of local high concentrations of EGF at the cell-matrix interface. As we all know, basic fibroblast growth factor (bFGF) can not only enhance the proliferation of MSCs but also promote the differentiation of MSCs in different directions (Rodrigues et al., 2010). In order to accurately mimic the release concentration of bFGF in 
injured ligament/tendon, Sahoo et al. (2010) incorporated bFGFreleasing PLGA fibers to the surface of the knitted silk scaffold, and the biological concentration of $6.5-13.5 \mathrm{pg} / \mathrm{ml}$ of bFGF in bioactive form was successfully recovered. Compared with bFGF (-) scaffold, MSCs in bFGF (+) scaffold exhibited higher viability (increased by 25\%) during the whole culture process. Moreover, the gene expression level of ECM protein in the bFGF $(+)$ scaffold such as type I and III collagens, fibronectin, and the deposition of soluble collagen were significantly increased. These results indicated that the released bFGF has broad application prospects in repairing tendon and ligament injury by promoting proliferation and tenogenic differentiation. On the other hand, vascularization of grafts plays a very important role in tissue repair and vascular endothelial growth factor (VEGF) is an essential growth factor in regular angiogenesis (Davies et al., 2008). Khojasteh et al. (2016) fabricated a porous scaffold with VEGF controlled release and proved that the proliferation and attachment of MSCs were significantly increased than those without VEGF. Meanwhile, they found that the gene expression of COL I and RUNX2 for osteogenesis and that of vWF and VEGFR2 for angiogenesis were statistically increased, demonstrating that VEGF not only promoted angiogenesis but also played an important role in bone repair. Besides, TGF $\beta$ is also a known superfamily that can affect the chondrogenic differentiation and matrix deposition of MSCs in vivo (Rodrigues et al., 2010). Therefore, lots of studies have integrated TGF $\beta$ into the scaffold to explore its prospects in cartilage repair. Re'em et al. (2012) developed a scaffold with TGF $\beta$ sustained release, and the chondrocytes with deposited type II collagen were only found in the TGF $\beta$ bound constructs compared to the naked one. Therefore, the use of biomaterials to deliver growth factors to regulate MSCs behavior provides a viable means for tissue regeneration.

Because MSCs are regulated by a variety of regulatory factors in vivo, the combination of multiple biological factors on a biomaterial or delivery system is also a promising approach. Moreover, the synergistic effect on target cells is the characteristic of integrating multiple factors into one system. For example, Simmons et al. (2004) fabricated a dual growth factor delivery alginate hydrogel scaffold in which bone morphogenetic protein2 (BMP2) and transforming growth factor- $\beta 3$ (TGF- $\beta 3$ ) are incorporated. The scaffold supported the simultaneous release of important growth factors during osteogenesis from MSCs, and the dual delivery system showed more efficient and more effective tissue regeneration in vivo compared to the individual delivery. In another research, insulin-like growth factor-1 (IGF-1) and TGF- $\beta 1$ were loaded together in gelatin microparticles (Park et al., 2009). Then, the gelatin microparticles and rabbit marrow MSCs were assembled into an injectable hydrogel. Over the culture time in vitro, TGF- $\beta 1$ was gradually found to accelerate chondrogenic differentiation of MSCs, while IGF-1 promoted cell aggregation. The incorporation of the two growth factors showed a synergistic effect on chondrogenesis of MSCs, which provided a great potential for cartilage regeneration and repair. The above studies showed the advantages of multiple factor delivery biomaterials; thus, how to construct a novel system to provide appropriate combination of multiple growth factors or simulants is an inevitable trend in future researches and even clinical applications (Richardson et al., 2001).

However, due to the immunogenicity and short half-life, the integration of large protein growth factor into polymer scaffolds has certain limitations (Cai et al., 2014). Growth factor derivatives and peptides are short peptide sequences that mimic the receptorbinding or functional domains of growth factors (Liu et al., 2012). These short peptides can bind to corresponding receptors to activate intracellular pathways to achieve the effect of growth factors, while avoiding the obstacles of large proteins. Currently, it has been reported that short peptides such as QK, KLT, PRG, and the RGD can achieve this goal, and RGD sequence has been extensively tethered to biomaterials to regulate MSC behaviors for tissue repair (Liu et al., 2012; Lam and Segura, 2013; Cai et al., 2014; Rao et al., 2020). Yang et al. (2005) covalently incorporated different dosage adhesion peptides Arg-Gly-Asp (RGD) into hydrogel and found that the expression of bonerelated markers ALP and OCN was significant higher in RGDconjugated hydrogel than the control. Furthermore, the level of gene expression was positively correlated with the concentration of RGD. Consistent with Yang, the RGD peptide was bound to the surface of the scaffold by Qu et al. (2010). Compared with the unmodified scaffold, more MSCs adhered to RGD scaffolds after $4 \mathrm{~h}$ of culture. Moreover, after 14 days of culture, the RGD-modified scaffolds significantly promoted the osteogenesis of MSCs. These studies show that the growth factor derivatives and short peptide factor have good prospects and operability in regulating the behavior of MSCs.

\section{Small Bioactive Molecules}

Small bioactive molecules, such as nitric oxide, oxygen, and metallic ions, also have significant effects on MSCs behavior. Since 1977, Arnold et al. (1977) discovered that NO could participate in various physiological processes by activating the cyclic guanosine monophosphate (cGMP), and it has been intensively studied in cardiovascular homeostasis, tissue repair, and immunomodulation. Yao and his group cultured adipose-derived MSCs in a hydrogel that can release NO molecule continuously and transplanted the hydrogel into murine myocardial infarction (MI) models, which achieved positive therapeutic effects (Yao et al., 2015). It has been widely confirmed that the protective effect of MSCs on MI is mainly achieved through the pro-angiogenic cytokines it secreted (Berardi et al., 2011). Similarly, Yao and co-workers discovered that NO hydrogel remarkably enhanced the paracrine and the VEGF secretion of MSCs. Finally, these cytokines improved heart function by promoting vascularization and reducing ventricular remodeling. In another approach, the effects of NO on other aspects of MSCs was observed by Xing et al. (2013). He fabricated a gelatin hydrogel that can release nitric oxide at a physiological concentration, and lower attachment and proliferation efficiency of MSCs were obtained on the NO hydrogel compared to the control after incubating for $72 \mathrm{~h}$. Therefore, utilizing NO to modify the scaffold can improve antithrombotic ability by reducing cell adhesion and proliferation, which can be used as a coating material for repairing vascular injury. However, the instability of $\mathrm{NO}$ and its oxidation potential to the toxic 
nitrogen dioxide molecule is still the barrier to extremely exploit the therapeutic effects of NO (Xiao et al., 2017). So, the development of a more secure and stable delivery system becomes a breakthrough of the next-generation NO-based biomaterials.

Oxygen level is also a critical regulator of stem cell behavior. At present, MSCs are usually cultured in an incubator under an oxygen level of $20 \% \mathrm{pO}_{2}$, whereas the residing niche MSCs are in low oxygen tension $\left(1-7 \% \mathrm{pO}_{2}\right)$ (D'Ippolito et al., 2006). Therefore, more and more studies have examined the effects of oxygen level on MSCs. It is already known that low oxygen tension (hypoxia) can not only maintain the stemness of stem cells but also influence their proliferation and differentiation (Mohyeldin et al., 2010). Zhou et al. (2014) seeded bone marrow-derived MSCs into scaffold and cultured in different oxygen tension, and the MSCs under hypoxia (5\% $\mathrm{pO}_{2}$ ) exhibited a higher proliferation response compared with the others cultured under normoxic conditions $\left(20 \% \mathrm{pO}_{2}\right)$ on day 4 and 10. Meanwhile, higher levels of Runx2, Bmp2, BMP, and VEGF were observed in the hypoxia scaffold relative to the normoxic scaffold, suggesting that the hypoxia is conducive to the osteogenesis and angiogenesis of MSCs. In addition, Tong et al. (2016) demonstrated that hypoxic pretreated MSCcontaining biomimetic scaffold observably accelerated wound healing in diabetic rat ulcer. The reason is that hypoxia pretreatment can enhance the secretion of proangiogenic factors and angiogenesis of MSCs.

As cofactors of enzymes, various metal ions are widely involved in tissue homeostasis and participated in lots of chain reactions related to cell signaling pathways (Gérard et al., 2010). In recent years, more and more evidences showed that metallic ions also play an important role in the field of regenerative medicine by regulating MSCs behavior. Meanwhile, the integration of metal ions into bioactive scaffolds generated a dual function for matrix and enhanced its therapeutic effect (Mouriño et al., 2012). The main reasons were due to the fact that these ions released from the scaffold can stimulate various processes, including proliferation, attachment, and differentiation. For example, the enhanced osteogenic differentiation was observed on a silicon-releasable scaffold, and the silicon species in the scaffold was regarded to promote the alkaline phosphatase (ALP) and osteogenesis (Obata and Kasuga, 2009). The silver nanoparticles were also found to promote the proliferation and osteogenesis of MSCs in vitro, and the improved bone fracture healing was obtained through a novel collagen reinforced by silver nanoparticles (Zhang et al., 2015). Therefore, a comprehensive understanding of the effects of metal particles on MSC behaviors is necessary for the development of metal ion-integrated biomaterials. Table 1 summarizes the effects of different metallic ions on the behavior of MSCs. However, achieving sustained release of metal ions under suitable concentration and without systemic toxicity remains difficult as the complexity of manufacturing process is still a challenge for these strategies based on controlled metal release.

\section{Genetic Regulators}

Recently, great achievement has been made in regulating the behaviors of cells by integrating genetic regulatory factors into biomaterials. For example, the improved cell proliferation, enhanced osteogenesis, and high-quality healing of large-scale bone defects were obtained by a type of multi-functional scaffold containing phBMP-4 through controlled and sustained gene expression (Cui et al., 2020). The successful delivery of genes based on viral and non-viral means plays a great role in geneticbased tissue engineering (Huard et al., 2003; Giatsidis et al., 2013; Mellott et al., 2013). Currently, non-viral vectors are more preferred for gene therapy because viral vectors are immunogenic and carry the risk of infection and cytotoxicity (Giatsidis et al., 2013). Moreover, the physical non-viral transfection methods such as electroporation significantly improved the transfection efficiency to control the cellular behavior during tissue regeneration (Mellott et al., 2013). Here, we review the effects of genetic regulatory factors (such as complementary DNA and small interfering RNA) on MSCs.

Complementary DNA (cDNA) is a nucleic acid sequence that can encode specific proteins by reverse transcription in transfected cells. It has been reported that various specific proteins including VEGF (Huang et al., 2005), EGF (You and Nam, 2013), bFGF (Yau et al., 2007), BMP (Meinel et al., 2006; Wegman et al., 2011), and hepatocyte growth factors (HGFs) (Lu et al., 2013) can guide behaviors of MSCs through transfecting corresponding cDNA. Wegman et al. (2011) achieved osteogenic differentiation of MSCs in vitro and in vivo through prolonging expression of BMP-2 through plasmid DNA-based gene therapy. They incorporated the BMP-2 cDNA into an alginate hydrogel, and seeded MSCs into the hydrogel before implanting to naked mice. In the end, the continuous expression of BMP-2 protein significantly promoted the osteogenic differentiation of MSCs, which was also verified by the increased expression of ALP and the deposition of collagen I and osteocalcin. In another study, Moon et al. (2014) fabricated modified polyethyleneimine (PEI) conjugates to deliver VEGF CDNA and demonstrated that VEGFMSCs enhanced capillary formation in the infarcted area and attenuated ventricular remodeling in the model of MI.

Small interfering RNA is a small double-stranded RNA sequence (21-23 nucleotides) that can silence and knock down target genes by complementary binding to the corresponding mRNA sequence. Therefore, siRNA may provide another effective intervention to guide stem cell behavior in regenerative medicine applications (Benoit and Boutin, 2012). Jia et al. (2014) integrated two small interfering RNAs into the chitosan sponge, one targeting casein kinase 2 interaction protein 1 (siCkip-1) and another targeting soluble VEGF receptor 1 (siFLT-1), and osteogenesis and angiogenesis were observed in vitro and in vivo after co-culturing with MSCs. Moreover, they pointed out that the osteogenesis may be due to the targeted knockdown of Ckip-1 that markedly activates the signaling pathways related to bone morphogenetic proteins. At the same time, silencing soluble VEGF receptor 1 gene eventually upregulated the release of VEGF, which promoted the angiogenesis of MSCs. Similarly, we can also see the same phenomenon in the research of Nagai (Nagane et al., 2010). The author transformed the osteogenesis of MSCs to adipogenesis through culturing MSCs with the siRNAcontaining cationic dextran. The reason was that the siRNA here can knock down the activity of transcription coactivator 
PDZ-binding motif (TAZ), thus significantly promoting the osteogenesis of MSCs rather than adipogenesis.

\section{POTENTIAL OF COMBINING BIOCHEMICAL AND BIOPHYSICAL CUES}

Because the biophysical and biochemical signals exist simultaneously and cooperate together in vivo, combining their effects in vitro as an alternative solution has become an increasingly clear and affirmative topic in the field of cellular therapy and regenerative medicine. More importantly, several groups have proved the feasibility of combining the effects of biophysical and biochemical signals in vitro. For example, a novel osteogenic polypeptide hydrogel (GelMA-c-OGP) in which GelMA enabled the formation of hydrogel with mechanical properties, combined with osteogenic growth peptides (OGP) through co-cross-linking that continuously release during the bone defect healing period, was created by Qiao et al. (2020). Finally, the interaction of the two parameters promoted the bone formation procedure of osteogenic precursor cells in vitro, and more collagen fibers were observed to connect with cortical bones after implantation. In another study, an in vitro model

TABLE 1 | Effects of metallic ions on MSCs.

\begin{tabular}{|c|c|c|c|c|}
\hline Ion & Ionic form & Experimental trial & Effects on behaviors & References \\
\hline Silicon & $\begin{array}{l}\text { Glass microspheres (BGMs) } \\
\text { Silicon-releasable scaffold } \\
\text { Composite hydrogel }\end{array}$ & $\begin{array}{l}\text { In vitro } \\
\text { In vitro } \\
\text { In vitro/vivo }\end{array}$ & $\begin{array}{l}\text { Enhanced the attachment and proliferation of human } \\
\text { MSCs } \\
\text { Induce and enhance the osteogenic differentiation of } \\
\text { MSCs } \\
\text { Angiogenesis and adipogenesis }\end{array}$ & $\begin{array}{l}\text { Lei et al., } 2011 \\
\text { Obata and Kasuga, } 2009 \\
\text { Wang et al., } 2018\end{array}$ \\
\hline Calcium & Calcium phosphate composition & In vitro & $\begin{array}{l}\text { High mobility of focal adhesion, osteogenesis without } \\
\text { induce medium }\end{array}$ & Muller et al., 2008 \\
\hline Cobalt & $\begin{array}{l}\text { Cobalt chloride composition } \\
\text { Cobalt chloride composition } \\
\text { Cobalt chloride solution }\end{array}$ & $\begin{array}{l}\text { In vitro } \\
\text { In vitro } \\
\text { In vitro }\end{array}$ & $\begin{array}{l}\text { Increase the chondrogenic markers such as SOX9, } \\
\text { COL2A1, VCAN, ACAN } \\
\text { Induce neuronal differentiation } \\
\text { Enhance migration of MSCs }\end{array}$ & $\begin{array}{l}\text { Teti et al., } 2018 \\
\text { Jeon et al., } 2014 \\
\text { Yu et al., } 2013\end{array}$ \\
\hline Copper & Copper-histidine complex & In vitro & $\begin{array}{l}\text { Modify differentiation and proliferation by different } \\
\text { concentrations }\end{array}$ & Rodriguez et al., 2002 \\
\hline Zinc & Zinc-added bioactive glass & In vitro & Induce growth and osteogenic differentiation of MSCs & Oh et al., 2011 \\
\hline Vanadium & $\begin{array}{l}\text { Vanadium-loaded collagen scaffold } \\
\text { Vanadium-released scaffold }\end{array}$ & $\begin{array}{l}\text { In vitro } \\
\text { In vitro/vivo }\end{array}$ & $\begin{array}{l}\text { Adhesion, growth, differentiation } \\
\text { Endochondral ossification and angiogenesis in vivo. }\end{array}$ & $\begin{array}{l}\text { Cortizo et al., } 2016 \\
\text { Schussler et al., } 2017\end{array}$ \\
\hline Strontium & $\begin{array}{l}\text { Strontium-ranelate solution } \\
\text { Strontium-collagen scaffold }\end{array}$ & $\begin{array}{l}\text { In vitro } \\
\text { In vitro/vivo }\end{array}$ & $\begin{array}{l}\text { Osteogenic induction of MSCs at appropriate } \\
\text { concentration } \\
\text { Enhance osteogenic differentiation and bone formation }\end{array}$ & $\begin{array}{l}\text { Sila-Asna et al., } 2007 \\
\text { Yang et al., } 2011\end{array}$ \\
\hline Iron & Iron oxide nanoparticles & In vitro & Accelerate cell cycle progression, promote cell growth & Huang et al., 2009 \\
\hline Magnesium & $\begin{array}{l}\text { Magnesium-extract solution } \\
\text { Magnesium alloys extracts }\end{array}$ & $\begin{array}{l}\text { In vitro } \\
\text { In vitro }\end{array}$ & $\begin{array}{l}\text { Cell proliferation, osteoblastic differentiation } \\
\text { Enhance proliferation and osteogenic differentiation }\end{array}$ & $\begin{array}{l}\text { Luthringer and } \\
\text { Willumeit-Romer, } 2016 \\
\text { Li et al., } 2014\end{array}$ \\
\hline Silver & $\begin{array}{l}\text { Silver nanoparticles } \\
\text { Silver nanoparticles }\end{array}$ & $\begin{array}{l}\text { In vitro } \\
\text { In vitro/vivo }\end{array}$ & $\begin{array}{l}\text { Induce MSCs activation at appropriate concentration } \\
\text { Promote the proliferation and osteogenesis of MSCs }\end{array}$ & $\begin{array}{l}\text { Greulich et al., } 2009 \\
\text { Zhang et al., } 2015\end{array}$ \\
\hline
\end{tabular}

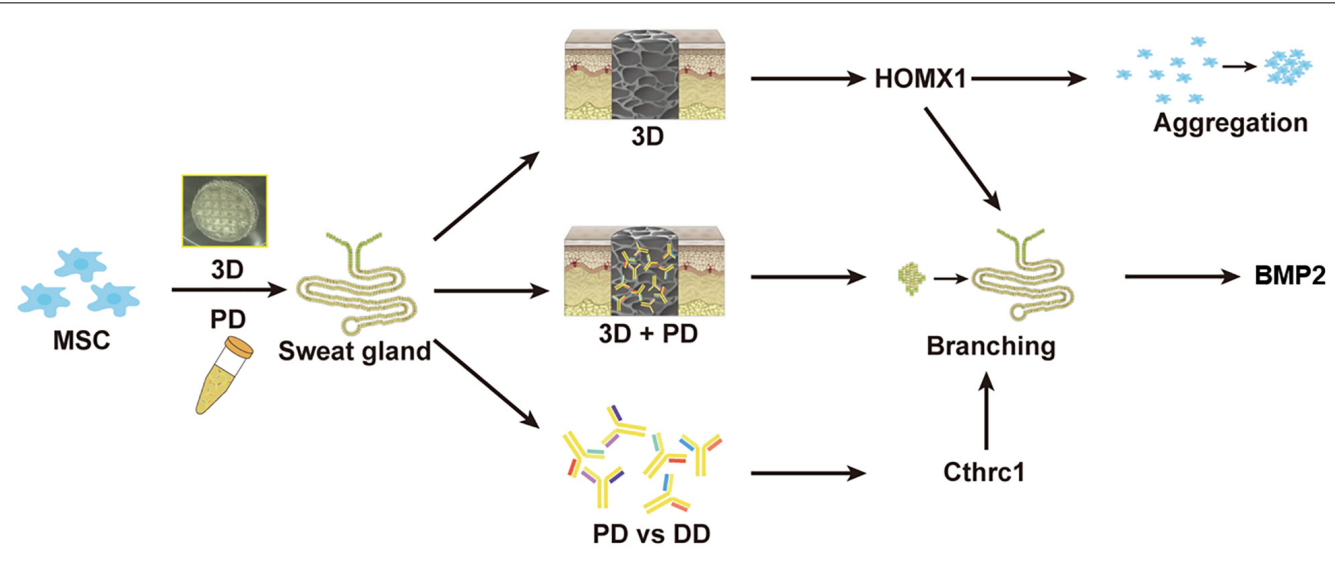

FIGURE 2 | The graphic illustration of 3D bioprinted matrix-directed MSC differentiation. CTHRC1 is the main biochemical cue during SG development and structural cues upregulated the expression of hmox1, synergistically initiating branching morphogenesis of SG. 
system combining biochemical and biophysical factors was found to be more effective on cardiomyocyte differentiation from rat bone marrow-MSCs (BM-MSCs) than any single factor alone (Ge et al., 2009).

In recent years, 3D bioprinting offers a promising and alternative platform to fabricate tissue-specific constructs for tissue repair and regeneration. These $3 \mathrm{D}$ functional constructs are regarded as the most biomimetic module due to the fact that they can provide both biochemical cues and biophysical signals to regulate cell-cell and cell-ECM interaction. In our previous work, by 3D bioprinted specific sweat gland (SG) matrix, we can differentiate MSCs into functional SGs by combination of biochemical and structural cues (Figure 2). The 3D printed
SG-like matrix provided a novel strategy to combine chemical factor, especially the collagen triple helix repeat containing 1 (CTHRC1), and 3D structural factor (Yao et al., 2020). These two cues synergistically directed MSCs' commitments into the glandular lineage and functional SG recovery in vitro and vivo. In addition, 3D bioprinting of tissue-specific decellularized extracellular matrix (dECM) bioink can provide a complex sitespecific combination of biochemical and mechanical cues, which have been hypothesized to prove their potential application in tissue engineering.

In addition to the synergistic effects, some researches have revealed the competitive relationship between the biophysical cues and the biochemical cues. For example, human bone

TABLE 2 | Effects of biomaterials on MSCs.

\begin{tabular}{|c|c|c|c|}
\hline Category & & $\begin{array}{l}\text { Effects on } \\
\text { behaviors }\end{array}$ & References \\
\hline \multirow[t]{14}{*}{ Biophysical } & Stiffness & Proliferation & Whitehead et al., 2018 \\
\hline & & Spreading & Engler et al., 2006; Wingate et al., 2012 \\
\hline & & Differentiation & Du et al., 2011; Shih et al., 2011; Higuchi et al., 2013; Sun et al., 2018 \\
\hline & Stress relaxation & Proliferation & Cameron et al., 2011; Chaudhuri et al., 2016 \\
\hline & & Spreading & Cameron et al., 2011; Chaudhuri et al., 2016 \\
\hline & & Differentiation & Cameron et al., 2011, 2014; Darnell et al., 2017 \\
\hline & Topography & Proliferation & Zhu et al., 2005; Jahani et al., 2012 \\
\hline & & Spreading & McBeath et al., 2004 \\
\hline & & Differentiation & McBeath et al., 2004; Kilian et al., 2010; Tang et al., 2010 \\
\hline & & Paracrine & Li et al., 2019 \\
\hline & Pore size and porosity & Proliferation & Mygind et al., 2007; Zhang et al., 2016; Zhao et al., 2021 \\
\hline & & Differentiation & Mygind et al., 2007; Kasten et al., 2008; Matsiko et al., 2015 \\
\hline & & Adhesion & Murphy et al., 2016; Zhang et al., 2016 \\
\hline & & Migration & O’Brien et al., 2007 \\
\hline \multirow[t]{19}{*}{ Biochemical } & Growth factor and derivatives & Proliferation & Rodrigues et al., 2010; Sahoo et al., 2010; Khojasteh et al., 2016 \\
\hline & & Differentiation & $\begin{array}{l}\text { Simmons et al., 2004; Park et al., 2009; Rodrigues et al., 2010; } \\
\text { Sahoo et al., 2010; Re'em et al., 2012; Khojasteh et al., 2016; } \\
\text { Rao et al., 2020; Zhu et al., } 2020\end{array}$ \\
\hline & & Paracrine & Tamama et al., 2010 \\
\hline & & Spreading & Fan et al., 2007; Lam and Segura, 2013 \\
\hline & & Adhesion & Fan et al., 2007; Qu et al., 2010; Khojasteh et al., 2016 \\
\hline & Small bioactive molecules (nitric oxide) & Immunomodulation & Yao et al., 2015 \\
\hline & & Paracrine & Berardi et al., 2011 \\
\hline & & Differentiation & Berardi et al., 2011 \\
\hline & & Adhesion & Xing et al., 2013 \\
\hline & & Proliferation & Xing et al., 2013 \\
\hline & Small bioactive molecules (oxygen level) & Proliferation & Zhou et al., 2014 \\
\hline & & Differentiation & Zhou et al., 2014; Tong et al., 2016 \\
\hline & & Paracrine & Tong et al., 2016 \\
\hline & Small bioactive molecules (metallic ions) & Table 1 & \\
\hline & Genetic regulators (cDNA) & Differentiation & Huang et al., 2005; Meinel et al., 2006; Yau et al., 2007; Lu et al., 2013 \\
\hline & & Proliferation & You and Nam, 2013 \\
\hline & & Migration & You and Nam, 2013 \\
\hline & & Paracrine & Moon et al., 2014 \\
\hline & Genetic regulators (siDNA) & Differentiation & Nagane et al., 2010; Jia et al., 2014 \\
\hline \multirow[t]{3}{*}{ Combined strategy } & Mechanical property and polypeptides & Differentiation & Bauer et al., 2017 \\
\hline & Strain and biochemical extract factors & Differentiation & Ge et al., 2009 \\
\hline & 3D microenvironment and biochemical & Differentiation & Yao et al., 2020 \\
\hline
\end{tabular}


marrow-derived MSCs were cultured on the nanostructured surface in differentiation media by McMurray et al. (2011). Compared with the cells cultured in the inductive medium alone, one interesting phenomenon was that the cells on the surface of nano-patterned topography showed a higher degree of stemness maintenance and lower differentiation levels. The reason is probably that biophysical factors have a longer duration and lifetime, which could even convert the effects of biochemical stimulation (Ahsan and Nerem, 2010). However, it is not clear whether these two aspects will conflict with each other, as well as the extent and the underlying mechanism. Therefore, distinguishing the internal effects when biophysical and biochemical cues are used in combination is essential.

\section{CONCLUSION AND FUTURE PROSPECTS}

The key point of MSC-based therapy is to maintain the viability of MSCs and accurately guide their fate and functionalization at the injury site. However, once MSCs are separated from their niches, their phenotype, functionality, and viability can easily be distorted. Therefore, it is necessary to create highly mimicking native-room biomaterials or substrates for MSCs to maintain their properties and exhibit therapeutic effects. Here, the biophysical and biochemical factors that determine the behaviors of MSCs have been discussed. These different cues and different protocols utilized in a variety of studies have led to difficulties in obtaining clear conclusions about the effects on regulating the proliferation, adhesion, and differentiation of MSCs and ultimately affect the function of the target tissue. Therefore, a comprehensive and systematic understanding of these signals is essential for the synthesis of more advanced artificial biomaterials and tissue engineering. Table 2 summarizes the factors that fall into some categories.

Recent advances in the design and manufacture of biomaterials with tailoring parameter not only provide a versatile toolbox for bioengineering [e.g., embedded 3D bioprinting

\section{REFERENCES}

Ahsan, T., and Nerem, R. M. (2010). Fluid shear stress promotes an endotheliallike phenotype during the early differentiation of embryonic stem cells. Tissue Eng. Part A 16, 3547-3553. doi: 10.1089/ten.TEA.2010.0014

Arnold, W. P., Mittal, C. K., Katsuki, S., and Murad, F. (1977). Nitric oxide activates guanylate cyclase and increases guanosine 3':5'-cyclic monophosphate levels in various tissue preparations. Proc. Natl. Acad. Sci. USA 74, 3203-3207. doi: 10.1073/pnas.74.8.3203

Bauer, A., Gu, L., Kwee, B., Li, W. A., Dellacherie, M., Celiz, A. D., et al. (2017). Hydrogel substrate stress-relaxation regulates the spreading and proliferation of mouse myoblasts. Acta Biomater. 62, 82-90. doi: 10.1016/j.actbio.2017. 08.041

Benoit, D. S. W., and Boutin, M. E. (2012). Controlling mesenchymal stem cell gene expression using polymer-mediated delivery of siRNA. Biomacromolecules 13, 3841-3849. doi: 10.1021/bm301294n

Berardi, G. R. M., Rebelatto, C. K., Tavares, H. F., Ingberman, M., Shigunov, P., Barchiki, F., et al. (2011). Transplantation of SNAP-treated adipose tissuederived stem cells improves cardiac function and induces neovascularization (de Melo et al., 2019), co-fabrication (Jodat et al., 2020), and stereolithography (Kumar and Kim, 2020)] but also present a feasible approach for subsequent research. However, we believe that the development of the biomaterial for regenerative medicine needs to be combined with multidisciplinary research progress, and the biophysical and biochemical factors used to regulate MSC behaviors must be precisely integrated and adjusted according to the needs of the repair area. Just like Yasamin et al., they combined multi-material 3D bioprinting with electronic platform technology to synthesize a hybrid device that can not only reconstruct the mechanical structure of nasal cartilage but also sense odor (Jodat et al., 2020). The integration of the aforementioned multidisciplinary research can be a potential avenue toward achieving functional nasal regeneration and organ transplant. Therefore, we believe that the next-generation biomaterials with accurately integrated induction cues for MSCs will open a new window for perfect regeneration and simultaneous repair.

\section{AUTHOR CONTRIBUTIONS}

SH contributed to the conception of the study and edited the manuscript. JL and YL wrote the sections of the manuscript. All authors read and approved the submitted version.

\section{FUNDING}

This study was supported in part by the National Nature Science Foundation of China (81830064, 81721092, and 81701906), the National Key Research and Development Plan (2017YFC1103300), the CAMS Innovation Fund for Medical Sciences (CIFMS, 2019-I2M-5-059), the Military Medical Research and Development Projects (AWS17J005, 2019-126), the Fostering Funds of Chinese PLA General Hospital for National Distinguished Young Scholar Science Fund (2017JQPY-002), and the National Natural Science Foundation of China (82002056).

after myocardium infarct in rats. Exp. Mol. Pathol. 90, 149-156. doi: 10.1016/j. yexmp.2010.11.005

Cai, L., Dinh, C. B., and Heilshorn, S. C. (2014). One-pot synthesis of elastin-like polypeptide hydrogels with grafted VEGF-mimetic peptides. Biomater. Sci. 2, 757-765. doi: 10.1039/C3BM60293A

Cameron, A. R., Frith, J. E., and Cooper-White, J. J. (2011). The influence of substrate creep on mesenchymal stem cell behaviour and phenotype. Biomaterials 32, 5979-5993. doi: 10.1016/j.biomaterials.2011.04.003

Cameron, A. R., Frith, J. E., Gomez, G. A., Yap, A. S., and Cooper-White, J. J. (2014). The effect of time-dependent deformation of viscoelastic hydrogels on myogenic induction and Racl activity in mesenchymal stem cells. Biomaterials 35, 1857-1868. doi: 10.1016/j.biomaterials.2013.11.023

Chaudhuri, O., Gu, L., Darnell, M., Klumpers, D., Bencherif, S. A., Weaver, J. C., et al. (2015). Substrate stress relaxation regulates cell spreading. Nat. Commun. 6:6364. doi: 10.1038/ncomms7365

Chaudhuri, O., Gu, L., Klumpers, D., Darnell, M., Bencherif, S. A., Weaver, J. C., et al. (2016). Hydrogels with tunable stress relaxation regulate stem cell fate and activity. Nat. Mater. 15, 326-334. doi: 10.1038/nmat 4489 
Cortizo, A. M., Ruderman, G., Mazzini, F. N., Molinuevo, M. S., and Mogilner, I. G. (2016). Novel vanadium-loaded ordered collagen scaffold promotes osteochondral differentiation of bone marrow progenitor cells. Int. J. Biomater. 2016:1486350. doi: 10.1155/2016/1486350

Cui, L., Zhang, J., Zou, J., Yang, X., Guo, H., Tian, H., et al. (2020). Electroactive composite scaffold with locally expressed osteoinductive factor for synergistic bone repair upon electrical stimulation. Biomaterials 230:119617. doi: 10.1016/ j.biomaterials.2019.119617

Darnell, M., Young, S., Gu, L., Shah, N., Lippens, E., Weaver, J., et al. (2017). Substrate stress-relaxation regulates scaffold remodeling and bone formation in vivo. Adv. Healthc. Mater. 6:1601185. doi: 10.1002/adhm.201601185

Davies, N., Dobner, S., Bezuidenhout, D., Schmidt, C., Beck, M., Zisch, A. H., et al. (2008). The dosage dependence of VEGF stimulation on scaffold neovascularisation. Biomaterials 29, 3531-3538. doi: 10.1016/j.biomaterials. 2008.05.007

De Becker, A., and Riet, I. V. (2016). Homing and migration of mesenchymal stromal cells: how to improve the efficacy of cell therapy? World J. Stem Cells 8, 73-87. doi: 10.4252/wjsc.v8.i3.73

de Melo, B. A., Jodat, Y. A., Mehrotra, S., Calabrese, M. A., Kamperman, T., Mandal, B. B., et al. (2019). 3D printed cartilage-like tissue constructs with spatially controlled mechanical properties. Adv. Funct. Mater. 29:1906330. doi: 10.1002/adfm.201906330

Ding, J., Zhang, J., Li, J., Li, D., Xiao, C., Xiao, H., et al. (2019). Electrospun polymer biomaterials. Prog. Polym. Sci. 90, 1-34.

Discher, D. E., Janmey, P., and Wang, Y. -L. (2005). Tissue cells feel and respond to the stiffness of their substrate. Science 310, 1139-1143. doi: 10.1126/science. 1116995

Du, J., Chen, X., Liang, X., Zhang, G., Xu, J., He, L., et al. (2011). Integrin activation and internalization on soft ECM as a mechanism of induction of stem cell differentiation by ECM elasticity. Proc. Natl. Acad. Sci. U.S.A. 108, 9466-9471. doi: 10.1073/pnas.1106467108

Duarte Campos, D. F., Blaeser, A., Korsten, A., Neuss, S., Jäkel, J., Vogt, M., et al. (2015). The stiffness and structure of three-dimensional printed hydrogels direct the differentiation of mesenchymal stromal cells toward adipogenic and osteogenic lineages. Tissue Eng. Part A 21, 740-756. doi: 10.1089/ten.TEA.2014. 0231

Engler, A. J., Sen, S., Sweeney, H. L., and Discher, D. E. (2006). Matrix elasticity directs stem cell lineage specification. Cell 126, 677-689.

Fan, V. H., Tamama, K., Au, A., Littrell, R., Richardson, L. B., Wright, J. W., et al. (2007). Tethered epidermal growth factor provides a survival advantage to mesenchymal stem cells. Stem Cells 25, 1241-1251.

Ferrara, N., and Alitalo, K. (1999). Clinical applications of angiogenic growth factors and their inhibitors. Nat. Med. 5, 1359-1364. doi: 10.1038/70928

Ge, D., Liu, X., Li, L., Wu, J., Tu, Q., Shi, Y., et al. (2009). Chemical and physical stimuli induce cardiomyocyte differentiation from stem cells. Biochem. Biophy. Res. Commun. 381, 317-321.

Gérard, C., Bordeleau, L.-J., Barralet, J., and Doillon, C. J. (2010). The stimulation of angiogenesis and collagen deposition by copper. Biomaterials 31, 824-831. doi: 10.1016/j.biomaterials.2009.10.009

Giatsidis, G., Venezia, E. D., and Bassetto, F. (2013). The role of gene therapy in regenerative surgery: updated insights. Plast. Reconstr. Surg. 131, 1425-1435. doi: 10.1097/PRS.0b013e31828bd153

Gilbert, P. M., Havenstrite, K. L., Magnusson, K. E. G., Sacco, A., Leonardi, N. A., Kraft, P., et al. (2010). Substrate elasticity regulates skeletal muscle stem cell self-renewal in culture. Science 329, 1078-1081. doi: 10.1126/science.1191035

Greulich, C., Kittler, S., Epple, M., Muhr, G., and Koller, M. (2009). Studies on the biocompatibility and the interaction of silver nanoparticles with human mesenchymal stem cells (hMSCs). Langenbecks Arch. Surg. 394, 495-502. doi: 10.1007/s00423-009-0472-1

Gupte, M. J., Swanson, W. B., Hu, J., Jin, X., Ma, H., Zhang, Z., et al. (2018). Pore size directs bone marrow stromal cell fate and tissue regeneration in nanofibrous macroporous scaffolds by mediating vascularization. Acta Biomater. 82, 1-11. doi: 10.1016/j.actbio.2018.10.016

Han, Y., Li, X., Zhang, Y., Han, Y., Chang, F., and Ding, J. (2019). Mesenchymal stem cells for regenerative medicine. Cells 8:886. doi: 10.3390/cells 8080886

Higuchi, A., Ling, Q.-D., Chang, Y., Hsu, S.-T., and Umezawa, A. (2013). Physical cues of biomaterials guide stem cell differentiation fate. Chem. Rev. 113, 32973328. doi: $10.1021 / \mathrm{cr} 300426 \mathrm{x}$
Huang, D. M., Hsiao, J. K., Chen, Y. C., Chien, L. Y., Yao, M., Chen, Y. K., et al. (2009). The promotion of human mesenchymal stem cell proliferation by superparamagnetic iron oxide nanoparticles. Biomaterials 30, 3645-3651. doi: 10.1016/j.biomaterials.2009.03.032

Huang, Y.-C., Kaigler, D., Rice, K. G., Krebsbach, P. H., and Mooney, D. J. (2005). Combined angiogenic and osteogenic factor delivery enhances bone marrow stromal cell-driven bone regeneration. J. Bone Miner. Res. 20, 848-857.

Huard, J., Li, Y., Peng, H., and Fu, F. H. (2003). Gene therapy and tissue engineering for sports medicine. J. Gene. Med. 5, 93-108. doi: 10.1002/jgm.344

Jahani, H., Kaviani, S., Hassanpour-Ezatti, M., Soleimani, M., Kaviani, Z., and Zonoubi, Z. (2012). The effect of aligned and random electrospun fibrous scaffolds on rat mesenchymal stem cell proliferation. Cell J. 14, $31-38$.

Jeon, E. S., Shin, J. H., Hwang, S. J., Moon, G. J., Bang, O. Y., and Kim, H. H. (2014). Cobalt chloride induces neuronal differentiation of human mesenchymal stem cells through upregulation of microRNA-124a. Biochem. Biophys. Res. Commun. 444, 581-587. doi: 10.1016/j.bbrc.2014.01.114

Jia, S., Yang, X., Song, W., Wang, L., Fang, K., Hu, Z., et al. (2014). Incorporation of osteogenic and angiogenic small interfering RNAs into chitosan sponge for bone tissue engineering. Int. J. Nanomed. 9, 5307-5316. doi: 10.2147/IJN. S70457

Jodat, Y. A., Kiaee, K., Vela Jarquin, D., De la Garza Hernández, R. L., Wang, T., Joshi, S., et al. (2020). A 3D-printed hybrid nasal cartilage with functional electronic olfaction. Adv. Sci. 7:1901878. doi: 10.1002/advs.201901878

Kasten, P., Beyen, I., Niemeyer, P., Luginbühl, R., Bohner, M., and Richter, W. (2008). Porosity and pore size of beta-tricalcium phosphate scaffold can influence protein production and osteogenic differentiation of human mesenchymal stem cells: an in vitro and in vivo study. Acta Biomater. 4, 1904-1915. doi: 10.1016/j.actbio.2008.05.017

Khojasteh, A., Fahimipour, F., Eslaminejad, M. B., Jafarian, M., Jahangir, S., Bastami, F., et al. (2016). Development of PLGA-coated $\beta$-TCP scaffolds containing VEGF for bone tissue engineering. Mater. Sci. Eng. C Mater. Biol. Appl. 69, 780-788. doi: 10.1016/j.msec.2016.07.011

Kilian, K. A., Bugarija, B., Lahn, B. T., and Mrksich, M. (2010). Geometric cues for directing the differentiation of mesenchymal stem cells. Proc. Natl. Acad. Sci. U.S.A. 107, 4872-4877. doi: 10.1073/pnas.0903269107

Kumar, H., and Kim, K. (2020). Stereolithography 3D Bioprinting. Methods Mol. Biol. 2140, 93-108. doi: 10.1007/978-1-0716-0520-2_6

Lam, J., and Segura, T. (2013). The modulation of MSC integrin expression by RGD presentation. Biomaterials 34, 3938-3947. doi: 10.1016/j.biomaterials.2013. 01.091

Le, H., Xu, W., Zhuang, X., Chang, F., Wang, Y., and Ding, J. (2020). Mesenchymal stem cells for cartilage regeneration. J. Tissue Eng. 11:2041731420943839. doi: $10.1177 / 2041731420943839$

Lei, B., Chen, X., Han, X., and Li, Z. (2011). Unique physical-chemical, apatiteforming properties and human marrow mesenchymal stem cells (HMSCs) response of sol-gel bioactive glass microspheres. J. Mater. Chem. 21, 1272512734. doi: 10.1039/C1JM11547B

Li, R. W., Kirkland, N. T., Truong, J., Wang, J., Smith, P. N., Birbilis, N., et al. (2014). The influence of biodegradable magnesium alloys on the osteogenic differentiation of human mesenchymal stem cells. J. Biomed. Mater. Res. A 102, 4346-4357. doi: 10.1002/jbm.a.35111

Li, T., Ma, H., Ma, H., Ma, Z., Qiang, L., Yang, Z., et al. (2019). Mussel-inspired nanostructures potentiate the immunomodulatory properties and angiogenesis of mesenchymal stem cells. ACS Appl. Mater. Interfaces 11, 17134-17146. doi: 10.1021/acsami.8b22017

Li, W.-J. W.-J., Tuli, R., Okafor, C., Derfoul, A., Danielson, K. G. K. G., Hall, D. J. D. J., et al. (2005). A three-dimensional nanofibrous scaffold for cartilage tissue engineering using human mesenchymal stem cells. Biomaterials 26, 599-609. doi: 10.1016/j.biomaterials.2004.03.005

Liu, X., Wang, X., Horii, A., Wang, X., Qiao, L., Zhang, S., et al. (2012). In vivo studies on angiogenic activity of two designer self-assembling peptide scaffold hydrogels in the chicken embryo chorioallantoic membrane. Nanoscale 4, 2720-2727. doi: 10.1039/c2nr00001f

Lu, F., Zhao, X., Wu, J., Cui, Y., Mao, Y., Chen, K., et al. (2013). MSCs transfected with hepatocyte growth factor or vascular endothelial growth factor improve cardiac function in the infarcted porcine heart by increasing angiogenesis and 
reducing fibrosis. Int. J. Cardiol. 167, 2524-2532. doi: 10.1016/j.ijcard.2012. 06.052

Luthringer, B. J., and Willumeit-Romer, R. (2016). Effects of magnesium degradation products on mesenchymal stem cell fate and osteoblastogenesis. Gene 575, 9-20. doi: 10.1016/j.gene.2015.08.028

Matsiko, A., Gleeson, J. P., and O’Brien, F. J. (2015). Scaffold mean pore size influences mesenchymal stem cell chondrogenic differentiation and matrix deposition. Tissue Eng. Part A 21, 486-497. doi: 10.1089/ten.TEA.2013.0545

McBeath, R., Pirone, D. M., Nelson, C. M., Bhadriraju, K., and Chen, C. S. (2004). Cell shape, cytoskeletal tension, and RhoA regulate stem cell lineage commitment. Dev. Cell 6, 483-495.

McMurray, R. J., Gadegaard, N., Tsimbouri, P. M., Burgess, K. V., McNamara, L. E., Tare, R., et al. (2011). Nanoscale surfaces for the long-term maintenance of mesenchymal stem cell phenotype and multipotency. Nat. Mater. 10, 637-644. doi: $10.1038 /$ nmat 3058

Meinel, L., Hofmann, S., Betz, O., Fajardo, R., Merkle, H. P., Langer, R., et al. (2006). Osteogenesis by human mesenchymal stem cells cultured on silk biomaterials: comparison of adenovirus mediated gene transfer and protein delivery of BMP-2. Biomaterials 27, 4993-5002.

Mellott, A. J., Forrest, M. L., and Detamore, M. S. (2013). Physical non-viral gene delivery methods for tissue engineering. Ann. Biomed. Eng. 41, 446-468. doi: 10.1007/s10439-012-0678-1

Mohyeldin, A., Garzón-Muvdi, T., and Quiñones-Hinojosa, A. (2010). Oxygen in stem cell biology: a critical component of the stem cell niche. Cell Stem Cell 7, 150-161. doi: 10.1016/j.stem.2010.07.007

Moon, H.-H., Joo, M. K., Mok, H., Lee, M., Hwang, K.-C., Kim, S. W., et al. (2014). MSC-based VEGF gene therapy in rat myocardial infarction model using facial amphipathic bile acid-conjugated polyethyleneimine. Biomaterials 35, 1744-1754. doi: 10.1016/j.biomaterials.2013.11.019

Mouriño, V., Cattalini, J. P., and Boccaccini, A. R. (2012). Metallic ions as therapeutic agents in tissue engineering scaffolds: an overview of their biological applications and strategies for new developments. J. R. Soc. Interface 9, 401-419. doi: 10.1098/rsif.2011.0611

Muller, P., Bulnheim, U., Diener, A., Luthen, F., Teller, M., Klinkenberg, E. D., et al. (2008). Calcium phosphate surfaces promote osteogenic differentiation of mesenchymal stem cells. J. Cell. Mol. Med. 12, 281-291. doi: 10.1111/j.15824934.2007.00103.x

Murphy, C. M., Duffy, G. P., Schindeler, A., and O'Brien, F. J. (2016). Effect of collagen-glycosaminoglycan scaffold pore size on matrix mineralization and cellular behavior in different cell types. J. Biomed. Mater. Res. A 104, 291-304. doi: 10.1002/jbm.a.35567

Mygind, T., Stiehler, M., Baatrup, A., Li, H., Zou, X., Flyvbjerg, A., et al. (2007). Mesenchymal stem cell ingrowth and differentiation on coralline hydroxyapatite scaffolds. Biomaterials 28, 1036-1047.

Nagane, K., Jo, J. I., and Tabata, Y. (2010). Promoted adipogenesis of rat mesenchymal stem cells by transfection of small interfering RNA complexed with a cationized dextran. Tissue Eng. Part A 16, 21-31. doi: 10.1089/ten.TEA. 2009.0170

O’Brien, F. J., Harley, B. A., Waller, M. A., Yannas, I. V., Gibson, L. J., and Prendergast, P. J. (2007). The effect of pore size on permeability and cell attachment in collagen scaffolds for tissue engineering. Technol. Health Care $15,3-17$.

Obata, A., and Kasuga, T. (2009). Stimulation of human mesenchymal stem cells and osteoblasts activities in vitro on silicon-releasable scaffolds. J. Biomed. Mater. Res. Part A 91, 11-17.

Oh, S. A., Kim, S. H., Won, J. E., Kim, J. J., Shin, U. S., and Kim, H. W. (2011). Effects on growth and osteogenic differentiation of mesenchymal stem cells by the zinc-added sol-gel bioactive glass granules. J. Tissue Eng. 2010:475260. doi: $10.4061 / 2010 / 475260$

Park, H., Temenoff, J. S., Tabata, Y., Caplan, A. I., Raphael, R. M., Jansen, J. A., et al. (2009). Effect of dual growth factor delivery on chondrogenic differentiation of rabbit marrow mesenchymal stem cells encapsulated in injectable hydrogel composites. J. Biomed. Mater. Res. Part A 88, 889-897. doi: 10.1002/jbm.a. 31948

Prabhakaran, M. P., Venugopal, J. R., and Ramakrishna, S. (2009). Mesenchymal stem cell differentiation to neuronal cells on electrospun nanofibrous substrates for nerve tissue engineering. Biomaterials 30, 4996-5003. doi: 10.1016/j. biomaterials.2009.05.057
Qiao, Y., Liu, X., Zhou, X., Zhang, H., Zhang, W., Xiao, W., et al. (2020). Gelatin templated polypeptide co-cross-linked hydrogel for bone regeneration. $A d v$. Healthc. Mater. 9:e1901239. doi: 10.1002/adhm.201901239

Qu, Z., Yan, J., Li, B., Zhuang, J., and Huang, Y. (2010). Improving bone marrow stromal cell attachment on chitosan/hydroxyapatite scaffolds by an immobilized RGD peptide. Biomed. Mater. 5:065001. doi: 10.1088/1748-6041/ $5 / 6 / 065001$

Rao, F., Wang, Y., Zhang, D., Lu, C., Cao, Z., Sui, J., et al. (2020). Aligned chitosan nanofiber hydrogel grafted with peptides mimicking bioactive brain-derived neurotrophic factor and vascular endothelial growth factor repair long-distance sciatic nerve defects in rats. Theranostics 10, 1590-1603. doi: 10.7150/thno. 36272

Re'em, T., Kaminer-Israeli, Y., Ruvinov, E., and Cohen, S. (2012). Chondrogenesis of hMSC in affinity-bound TGF-beta scaffolds. Biomaterials 33, 751-761. doi: 10.1016/j.biomaterials.2011.10.007

Richardson, T. P., Peters, M. C., Ennett, A. B., and Mooney, D. J. (2001). Polymeric system for dual growth factor delivery. Nat. Biotechnol. 19, 1029-1034. doi: 10.1038/nbt1101-1029

Rodrigues, M., Griffith, L. G., and Wells, A. (2010). Growth factor regulation of proliferation and survival of multipotential stromal cells. Stem Cell Res. Ther. 1:32. doi: $10.1186 /$ scrt32

Rodriguez, J. P., Rios, S., and Gonzalez, M. (2002). Modulation of the proliferation and differentiation of human mesenchymal stem cells by copper. J. Cell. Biochem. 85, 92-100.

Sahoo, S., Toh, S. L., and Goh, J. C. H. (2010). A bFGF-releasing silk/PLGA-based biohybrid scaffold for ligament/tendon tissue engineering using mesenchymal progenitor cells. Biomaterials 31, 2990-2998. doi: 10.1016/j.biomaterials.2010. 01.004

Schussler, S. D., Uske, K., Marwah, P., Kemp, F. W., Bogden, J. D., Lin, S. S., et al. (2017). Controlled release of vanadium from a composite scaffold stimulates mesenchymal stem cell osteochondrogenesis. Aaps J. 19, 1017-1028. doi: 10. 1208/s12248-017-0073-9

Shih, Y. R. V., Tseng, K. F., Lai, H. Y., Lin, C. H., and Lee, O. K. (2011). Matrix stiffness regulation of integrin-mediated mechanotransduction during osteogenic differentiation of human mesenchymal stem cells. J. Bone Miner. Res. 26, 730-738. doi: 10.1002/jbmr.278

Sila-Asna, M., Bunyaratvej, A., Maeda, S., Kitaguchi, H., and Bunyaratavej, N. (2007). Osteoblast differentiation and bone formation gene expression in strontium-inducing bone marrow mesenchymal stem cell. Kobe J. Med. Sci. 53, 25-35.

Simmons, C. A., Alsberg, E., Hsiong, S., Kim, W. J., and Mooney, D. J. (2004). Dual growth factor delivery and controlled scaffold degradation enhance in vivo bone formation by transplanted bone marrow stromal cells. Bone 35 , $562-569$.

Sun, M., Chi, G., Xu, J., Tan, Y., Xu, J., Lv, S., et al. (2018). Extracellular matrix stiffness controls osteogenic differentiation of mesenchymal stem cells mediated by integrin $\alpha 5$. Stem Cell Res. Ther. 9:52. doi: 10.1186/s13287-0180798-0

Tamama, K., Kawasaki, H., and Wells, A. (2010). Epidermal growth factor (EGF) treatment on multipotential stromal cells (MSCs). possible enhancement of therapeutic potential of MSC. J. Biomed. Biotechnol. 2010:795385. doi: 10.1155/ 2010/795385

Tang, J., Peng, R., and Ding, J. (2010). The regulation of stem cell differentiation by cell-cell contact on micropatterned material surfaces. Biomaterials 31, 24702476. doi: 10.1016/j.biomaterials.2009.12.006

Tay, C. Y., Yu, H., Pal, M., Leong, W. S., Tan, N. S., Ng, K. W., et al. (2010). Micropatterned matrix directs differentiation of human mesenchymal stem cells towards myocardial lineage. Exp. Cell Res. 316, 1159-1168. doi: 10.1016/ j.yexcr.2010.02.010

Teti, G., Focaroli, S., Salvatore, V., Mazzotti, E., Ingra, L., Mazzotti, A., et al. (2018). The hypoxia-mimetic agent cobalt chloride differently affects human mesenchymal stem cells in their chondrogenic potential. Stem Cells Int. 2018:3237253. doi: $10.1155 / 2018 / 3237253$

Tong, C., Hao, H., Xia, L., Liu, J., Ti, D., Dong, L., et al. (2016). Hypoxia pretreatment of bone marrow-derived mesenchymal stem cells seeded in a collagen-chitosan sponge scaffold promotes skin wound healing in diabetic rats with hindlimb ischemia. Wound Repair Regen. 24, 45-56. doi: 10.1111/wrr. 12369 
Wan, L. Q., Kang, S. M., Eng, G., Grayson, W. L., Lu, X. L., Huo, B., et al. (2010). Geometric control of human stem cell morphology and differentiation. Integr. Biol. (Camb) 2, 346-353. doi: 10.1039/c0ib00016g

Wang, X., Gao, L., Han, Y., Xing, M., Zhao, C., Peng, J., et al. (2018). Silicon-enhanced adipogenesis and angiogenesis for vascularized adipose tissue engineering. Adv. Sci. 5:1800776. doi: 10.1002/advs.201800776

Weber, J. N., White, E. W., and Lebiedzik, J. (1971). New porous biomaterials by replication of echinoderm skeletal microstructures. Nature 233, 337-339. doi: $10.1038 / 233337 \mathrm{a} 0$

Wegman, F., Bijenhof, A., Schuijff, L., Oner, F. C., Dhert, W. J. A., and Alblas, J. (2011). Osteogenic differentiation as a result of BMP-2 plasmid DNA based gene therapy in vitro and in vivo. Eur. Cells Mater. 21, 230-242.

Whitehead, A. K., Barnett, H. H., Caldorera-Moore, M. E., and Newman, J. J. (2018). Poly (ethylene glycol) hydrogel elasticity influences human mesenchymal stem cell behavior. Regenerative Biomaterials 5, 167-175. doi: $10.1093 / \mathrm{rb} / \mathrm{rby} 008$

Wingate, K., Bonani, W., Tan, Y., Bryant, S. J., and Tan, W. (2012). Compressive elasticity of three-dimensional nanofiber matrix directs mesenchymal stem cell differentiation to vascular cells with endothelial or smooth muscle cell markers. Acta Biomater. 8, 1440-1449. doi: 10.1016/j.actbio.2011. 12.032

Xiao, Y., Ahadian, S., and Radisic, M. (2017). Biochemical and biophysical cues in matrix design for chronic and diabetic wound treatment. Tissue Eng. Part B Rev. 23, 9-26. doi: 10.1089/ten.TEB.2016. 0200

Xing, Q., Yates, K., Bailey, A., Vogt, C., He, W., Frost, M. C., et al. (2013). Effects of local nitric oxide release on human mesenchymal stem cell attachment and proliferation on gelatin hydrogel surface. Surf. Innov. 1, 224-232.

Yang, F., Williams, C. G., Wang, D. -A., Lee, H., Manson, P. N., and Elisseeff, J. (2005). The effect of incorporating RGD adhesive peptide in polyethylene glycol diacrylate hydrogel on osteogenesis of bone marrow stromal cells. Biomaterials 26, 5991-5998. doi: 10.1016/j.biomaterials.2005. 03.018

Yang, F., Yang, D., Tu, J., Zheng, Q., Cai, L., and Wang, L. (2011). Strontium enhances osteogenic differentiation of mesenchymal stem cells and in vivo bone formation by activating Wnt/catenin signaling. Stem Cells 29, 981-991. doi: $10.1002 /$ stem.646

Yao, B., Wang, R., Wang, Y., Zhang, Y., Hu, T., Song, W., et al. (2020). Biochemical and structural cues of $3 \mathrm{D}$-printed matrix synergistically direct MSC differentiation for functional sweat gland regeneration. Sci. Adv. 6:eaaz1094. doi: 10.1126/sciadv.aaz1094

Yao, X., Liu, Y., Gao, J., Yang, L., Mao, D., Stefanitsch, C., et al. (2015). Nitric oxide releasing hydrogel enhances the therapeutic efficacy of mesenchymal stem cells for myocardial infarction. Biomaterials 60, 130-140. doi: 10.1016/j.biomaterials. 2015.04.046

Yau, T. M., Kim, C., Li, G., Zhang, Y., Fazel, S., Spiegelstein, D., et al. (2007). Enhanced angiogenesis with multimodal cell-based gene therapy. Ann. Thorac. Surg. 83, 1110-1119.

You, D. H., and Nam, M. J. (2013). Effects of human epidermal growth factor genetransfected mesenchymal stem cells on fibroblast migration and proliferation. Cell Prolif. 46, 408-415. doi: 10.1111/cpr.12042

Yu, X., Lu, C., Liu, H., Rao, S., Cai, J., Liu, S., et al. (2013). Hypoxic preconditioning with cobalt of bone marrow mesenchymal stem cells improves cell migration and enhances therapy for treatment of ischemic acute kidney injury. PLoS One 8:e62703. doi: 10.1371/journal.pone.0062703

Zhang, R., Lee, P., Lui, V. C. H., Chen, Y., Liu, X., Lok, C. N., et al. (2015). Silver nanoparticles promote osteogenesis of mesenchymal stem cells and improve bone fracture healing in osteogenesis mechanism mouse model. Nanomed. Nanotechnol. Biol. Med. 11, 1949-1959. doi: 10.1016/j.nano.2015. 07.016

Zhang, Z. Z., Jiang, D., Ding, J. X., Wang, S. J., Zhang, L., Zhang, J. Y., et al. (2016). Role of scaffold mean pore size in meniscus regeneration. Acta Biomater. 43, 314-326. doi: 10.1016/j.actbio.2016.07.050

Zhao, D., Zhu, T., Li, J., Cui, L., Zhang, Z., Zhuang, X., et al. (2021). Poly(lacticco-glycolic acid)-based composite bone-substitute materials. Bioact. Mater. 6, 346-360. doi: 10.1016/j.bioactmat.2020.08.016

Zhou, Y., Guan, X., Yu, M., Wang, X., Zhu, W., Wang, C., et al. (2014). Angiogenic/osteogenic response of BMMSCs on bone-derived scaffold: effect of hypoxia and role of PI3K/Akt-mediated VEGF-VEGFR pathway. Biotechnol. J. 9, 944-953. doi: 10.1002/biot.201300310

Zhu, B., Lu, Q., Yin, J., Hu, J., and Wang, Z. (2005). Alignment of osteoblast-like cells and cell-produced collagen matrix induced by nanogrooves. Tissue Eng. 11, 825-834.

Zhu, T., Cui, Y., Zhang, M., Zhao, D., Liu, G., and Ding, J. (2020). Engineered threedimensional scaffolds for enhanced bone regeneration in osteonecrosis. Bioact. Mater. 5, 584-601. doi: 10.1016/j.bioactmat.2020.04.008

Conflict of Interest: The authors declare that the research was conducted in the absence of any commercial or financial relationships that could be construed as a potential conflict of interest.

Copyright $\odot 2021$ Li, Liu, Zhang, Yao, Enhejirigala, Li, Song, Wang, Duan, Yuan, Fu and Huang. This is an open-access article distributed under the terms of the Creative Commons Attribution License (CC BY). The use, distribution or reproduction in other forums is permitted, provided the original author(s) and the copyright owner(s) are credited and that the original publication in this journal is cited, in accordance with accepted academic practice. No use, distribution or reproduction is permitted which does not comply with these terms. 